\title{
Experimental Study of Transient Forced Convection Heat Transfer Nanofluid in Triangular Duct
}

\author{
Ahmed H. Ali ${ }^{1}$, Tahseen A.Al-Hattab ${ }^{2}$ \\ Department of Automotive, Technical College of Najaf, Najaf, Iraq ${ }^{1}$ \\ Department of Electrochemical Engineering, University of Babylon, Babylon, Iraq ${ }^{2}$
}

\begin{abstract}
The transient 3-D fully developed forced convection laminar flow of Cuo/water and $\mathrm{Al}_{2} \mathrm{O}_{3}$ with constant property in horizontal triangular duct has been thoroughly investigated experimentally. Four different values of Reynolds number $(500,1000,1500$ and 2000), volume fraction $(0.025,0.05,0.1$ and 0.25$) \%$ were used, and constant Heat Flux boundary condition was applied. Results are compared with theoretical data available in the literature in steady state condition, good agreements are showed. The results appeared that heat transfer rate become more remarkable when employing nanofluid than that of pure water. Also, Heat transfer enhancement increases with the particle volume concentration increase for a given other parameters, and considerable reduction in time consuming for steady state condition. Temperature difference distribution are presented for various void fractions and Reynolds numbers. in addition, friction factor, local and average Nusselt number are introduced for various Reynolds numbers and volume fraction of nanoparticles.
\end{abstract}

KEY WORDS: Triangular duct, Transient state, Forced Convection, nanofluid, Constant Heat Flux,

\section{INTRODUCTION}

The increase of heat transfer coefficient is one of the most important technical aims for industry and researches. The low thermal conductivity of conventional liquids such as water, oil, ethylene glycol etc. was major restriction for using it. The heat transfer rate can passively be improved by changing flow geometry, boundary conditions or by enhancing fluid thermo- physical properties.

consequently in recent years, add suspended nanoparticles(less than 100nm) sized will improve heat transfer ability because these nanoparticles have a better thermal performance compared to pure liquids. The metallic nanoparticles classify primary into two types, pure substance and oxides. Also, addition of these nanoparticles have no effect on friction factor due to a tiny scale compared to millimeters or microns which alter flow profile causing considerable increasing in pressure drop. So, nanofluids are more suitable for applications in which fluid flows through small passages as nanoparticles are small enough to behave likewise to liquid molecules.

\section{RELATED WORKS}

some studies revealed that nanofluids heat transfer coefficient could be increased by more than $20 \%$ also in the case of very low nanoparticles concentrations [1,2].actually, the reasons of such heat transfer improvement because the thickness reduction of the thermal boundary layer due to the adding of the nanoparticles and the arbitrary movement within the base fluid[3,4].

By increasing the nanofluid concentration, the heat transfer rate increases, because intensification of random motion will attached by increasing of interface and collision ratio. Also diffusion and relative movement of particles near the 


\section{International Journal of Innovative Research in Science, Engineering and Technology}

\section{(An ISO 3297: 2007 Certified Organization)}

\section{Vol. 3, Issue 8, August 2014}

wall leads to rapid heat transfer from wall to nanofluid. Use of nanofluids to augment the heat convection has some profit such as [5]:

- At the same system efficiency, decreasing of apparatus size.

- Augmentation of heat transfer rate

- Reduction of time consuming

- Decreasing of thermal apparatus cost and size

- Enhancement of cooling efficiency for very small equipments such as microprocessor, heat pipes, Microchannels and so on.

There are some articles available associated to investigation of convective heat transfer of nanofluids, most of them are based on experimental works. Li and Xuan [6,7]. offered an experimental investigation to study the friction factor and heat transfer coefficient of $\mathrm{Cu} / \mathrm{Water}$ nanofluid up to $2 \%$ volume fraction $\mathrm{An}$ increasing in Nusselt number ratio ( $\mathrm{Nu}$ when using nanofluid to that of pure fluid) up to $60 \%$ appeared at using nanofluid at $2 \%$ volume fraction of $\mathrm{Cu}$ according to their experimental results. Yang et al. [8]investigated experimentally effect of nanofluid on convective heat transfer in a horizontal tube heat exchanger. Some of particular parameters such as volume concentration Re, temperature and nanoparticles source on heat transfer have been studied. The results showed that direct increasing in heat transfer coefficient accompanied with the Re and particle void ratio.

An experimental investigation of oxide nanofluid laminar flow convective heat transfer, in circular tube were studied by Zeinali et al.[9,10] under constant heat flux. Results showed that Nusselt number increase when volume fraction increase for all Reynolds number. Nassan et. Al.[11] investigated heat transfer characteristics through a noncircular (square) cross-section duct in laminar flow experimentally. An effective augmentation of convective heat transfer coefficient for both nanofluids has been used.

Many numerical studies were achieved by investigators. Xuan and Roetzel [12] investigated heat transfer rate enhancement by adding nanoparticles. Results found that the nanofluid behaves more like a single-phase fluid because the discontinuous phase consists of ultrafine particles.

Also, zeinali et al. [13] were studied laminar flow-forced convective heat transfer of $\mathrm{Al}_{2} \mathrm{O}_{3} /$ water nanofluid in a triangular duct under constant wall temperature condition numerically. Results showed that Nusselt number increases with either increasing volume fraction or decreasing size of nanoparticles at the same concentration. Akbari et al. [14], presented a fully developed laminar mixed convection in 3-D elliptic coordinate Numerically. single-phase model in horizontal and inclined tubes with constant heat conducted. indicate that nanoparticles concentration have little effect on the secondary flow and axial velocity profile heat transfer enhancement has been achieved by nanofluids compared with base fluid.

ZeinaliHeris et al.[15] are presented numerical investigation on laminar forced convection in three different nanofluids, flowing in a square cross-sectioned duct. Results proved that increase values of particle concentration is the main cause of increasing in average heat transfer coefficient and Nusselt number. Moghari et al[16]estimated Heat transfer of a mixed convection laminar nanofluid flow in an annulus. The calculated results show that at a given $\mathrm{Re}$ and $\mathrm{Gr}$, increasing nanoparticles volume fraction increases the Nusselt number at the inner and outer walls.

The main aim of this study is investigation of the transient behavior of fully, laminar flow forced convection with various concentrations of nanoparticles and given Reynolds number on the heat transfer enhancement experimentally.

\section{EXPERMENTAL SETUP}

Fig.(1)shows the schematic of experimental setup configuration under consideration. The apparatus used in this experiment consists of a reservoir tanks, Teflon pump, By-pass line, test section, flow meter, cold water circuit and electrical heating circuit. The aim of using Teflon pump to prevent stick on nanoparticles with interior walls of pump. 


\section{IJIRSET \\ International Journal of Innovative Research in Science, Engineering and Technology}

ISSN: 2319-8753

\section{(An ISO 3297: 2007 Certified Organization)}

\section{Vol. 3, Issue 8, August 2014}

Two receiver tanks were used one for store nanofluids and hot working fluid leaving the test section $(10 \mathrm{~L})$ made from PVC and other for cooling water system $(20 \mathrm{~L})$. The test section was triangular duct has $(15.38 \mathrm{~mm})$ of each side height and $(2100 \mathrm{~mm})$ total length in flow direction. To calculate bulk temperature of working fluid, A two thermocouple (Ktype) were insert in both ends of test section to measure and store temperature during experiment. An additional eight Thermocouples from the same type are mounted on the surface of the tube at various longitudinal places. All thermocouples have $0.1{ }^{\circ} \mathrm{C}$ resolution and are calibrated before fixing them at the test section. The thermocouple wires are connected in parallel to twelve channel SD Card data recorder (BTM-4208 SD). The process of data saving implemented directly by SD-RAM. The main task of by-pass is to control on desired discharge and direct back excess nanofluids to PVS tank. The position of flow meter after test section ending to avoid the fluctuations that generate from

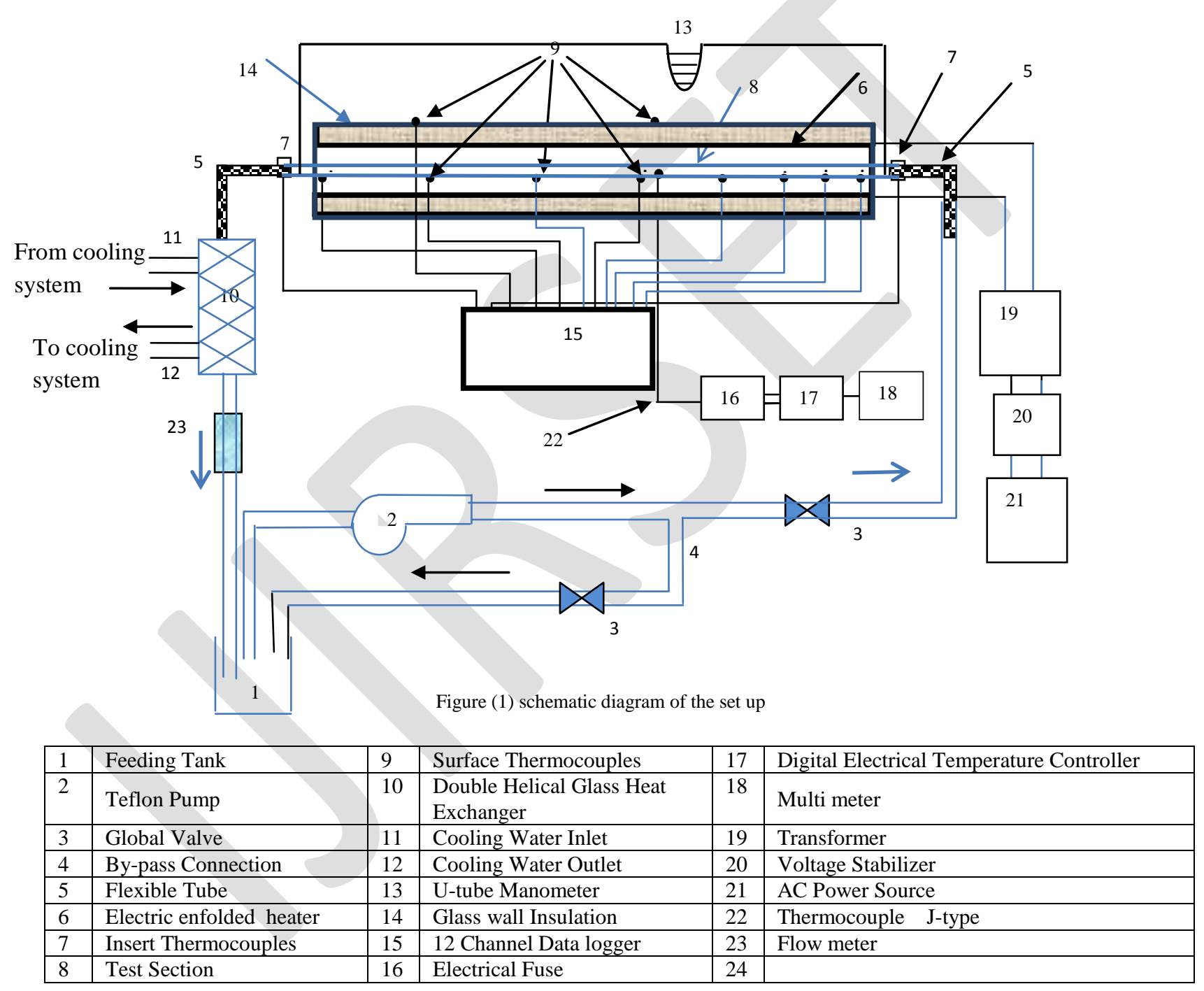

Teflon pump during operation. The duct, which are considered as a test section, heated by using an electrical heater circuit Fig. (2) to obtain the Constant Wall Temperature. Its consist of a tape heater (500 W and $18 \mathrm{~m})$ wound around tube and A Transformer(0-220V and 12A) to adjust the heater input power as required. A digital Multimeter (DW6060 ) is used to measure the heater power. in addition to, A Temperature Regulator is connected in series to an 


\section{International Journal of Innovative Research in Science, Engineering and Technology}

\section{(An ISO 3297: 2007 Certified Organization)}

\section{Vol. 3, Issue 8, August 2014}

automatically electrical fuse and (J-type) thermocouple soldered on outer tube wall to control the temperature in the desired values with an accuracy of $( \pm 0.1 \%)$ of the full scale. The triangular tube is thoroughly insulated with glass wool to avoid any heat outflow. The adding heat from the experiment will eliminate by cooling water supplied from cooling system in Fig. (3). Cooling water circuit Consist of Cold water tank, Compressor, plunger pump and double glass heat exchanger in parallel to augment heat transfer efficiency. Besides that, two static pressure taps are located along the side of the test section to measure the pressure drop across the section. throughout every experiment, the Re of the nanofluids and desired temperature were set until steady-state was reached.

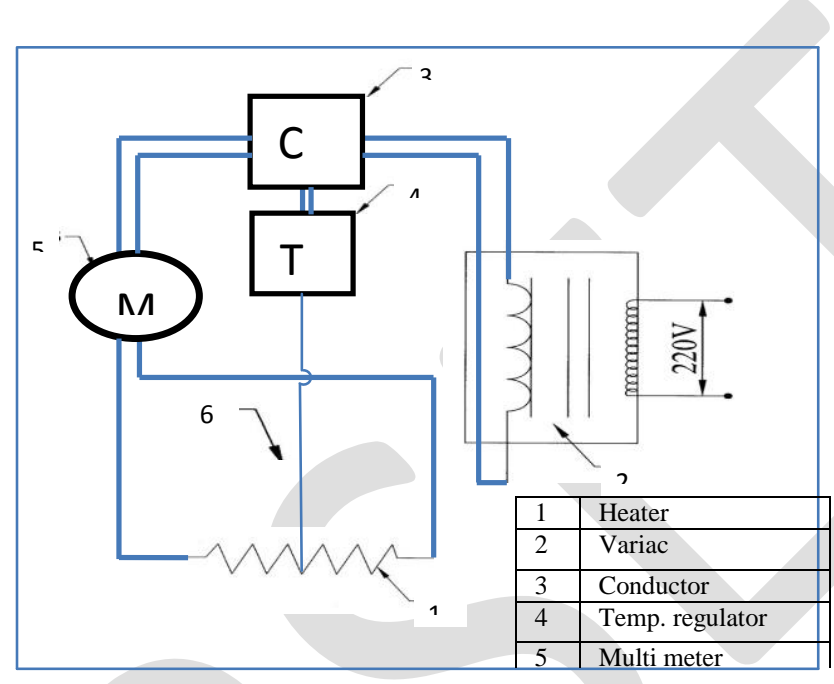

Figure (2) Temperature Controller Circuit

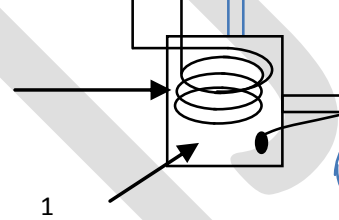

5

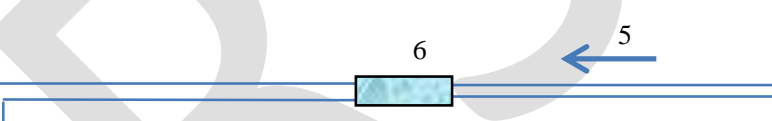

Figure (3) Schematic diagram of Cooling system

\begin{tabular}{|l|l|l|l|l|l|}
\hline 1 & Cold Water Tank & 6 & Flow meter & 11 & Compressor \\
\hline 2 & Electric Pump & 7 & Cooling Coil & 12 & fan \\
\hline 3 & valve & 8 & Sensor & 13 & Cooling Network \\
\hline 4 & Cooling water inlet & 9 & Electrical Fuse & & \\
\hline 5 & Cooling Water Outlet & 10 & Digital Electrical Temperature Controller & & \\
\hline
\end{tabular}


ISSN: 2319-8753

\title{
International Journal of Innovative Research in Science, Engineering and Technology
}

\author{
(An ISO 3297: 2007 Certified Organization) \\ Vol. 3, Issue 8, August 2014 \\ IV.EXPERMENTAL DATA ANALYSIS
}

Total input power supplied can be calculated from

$Q=I . V$

And the heat transfer absorbed by nanofluid is

$Q=\dot{m} C p\left(T_{\text {out }}-T_{\text {in }}\right)$

Where $\left(T_{\text {in }}\right)$ and $\left(T_{\text {out }}\right)$ are the inlet and outlet bulk temperature of nanofluid respectively.

The heat balance between heat flux supplied and heat flux calculated showed that the difference between them is not exceed 5\% due to high thermal conductivity of tube metal and good insulation. To examination of the heat transfer performance, convective heat transfer coefficient, is calculated as follow

$h_{n f}(\exp )_{x}=\frac{q}{A\left(\left(T_{w}\right)_{x}-\left(T_{b}\right)_{x}\right)}$

Where $\left(T_{b}\right)_{x}$ is the local bulk temperature and calculating by

$\left(T_{b}\right)_{x}=T_{\text {in }}+\frac{x}{L}\left(T_{\text {out }}-T_{\text {in }}\right)$

And local Nusselt number

$N u_{n f}(\exp )_{x}=\frac{h_{n f}(\exp )_{x} D_{h}}{k_{n f}}$

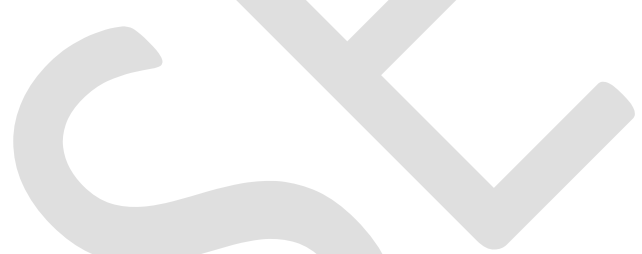

(4)

in the same way, the friction factor of the nanofluid flowing throughout the test section is estimated as

$f_{n f}=\frac{2 \Delta P_{n f}}{L} \frac{D_{h}}{\rho_{n f} u_{m}^{2}}$

All physical properties are evaluated for each Re at local mean temperature

\section{NANOFLUID PREPARATION AND VALIDATION}

Preparation of nanofluids is the first key step in applying nanophase particles to changing the heat transfer performance of conventional fluids. The physical properties of $\mathrm{CuO}$ and $\mathrm{AL}_{2} \mathrm{O}_{3}$ were taken from the manufacturer data sheet and listed in Table 1. Distilled water was used for the suspending liquid medium , and the equivalent weight of nanoparticles according to their volume was measured and gradually added to distilled water while agitated in flask. they were mixed with by a mechanical mixer(Stuart SS10), for thirty minutes. proper mixing, have utmost importance because of it offer a good dispersion and pre-stabilization of the particles, in addition to reduce time consuming to full stabilization. The suspensions were subjected to ultrasonic vibration (Elmasonic $\mathrm{P} 180 \mathrm{H}$ ) at $95 \%$ power and $40 \mathrm{kHz}$ for $60-90$ minutes to obtain uniform suspensions and collapse the bulky agglomerations. After this the prepared nanofluid is ready to use in the experimental test loop for taking the readings.

The preliminary test for consistency and accuracy of the set up with distillated water as the working fluid was performed before conducting the experiments on nanofluids. Figure (4) show The experimental results were comparing with the Zeinali et al. [13] . the figure below represent the comparison of Nusselt number values computed numerically with that determined values from the present work. 


\section{International Journal of Innovative Research in Science, Engineering and Technology}

(An ISO 3297: 2007 Certified Organization)

Vol. 3, Issue 8, August 2014

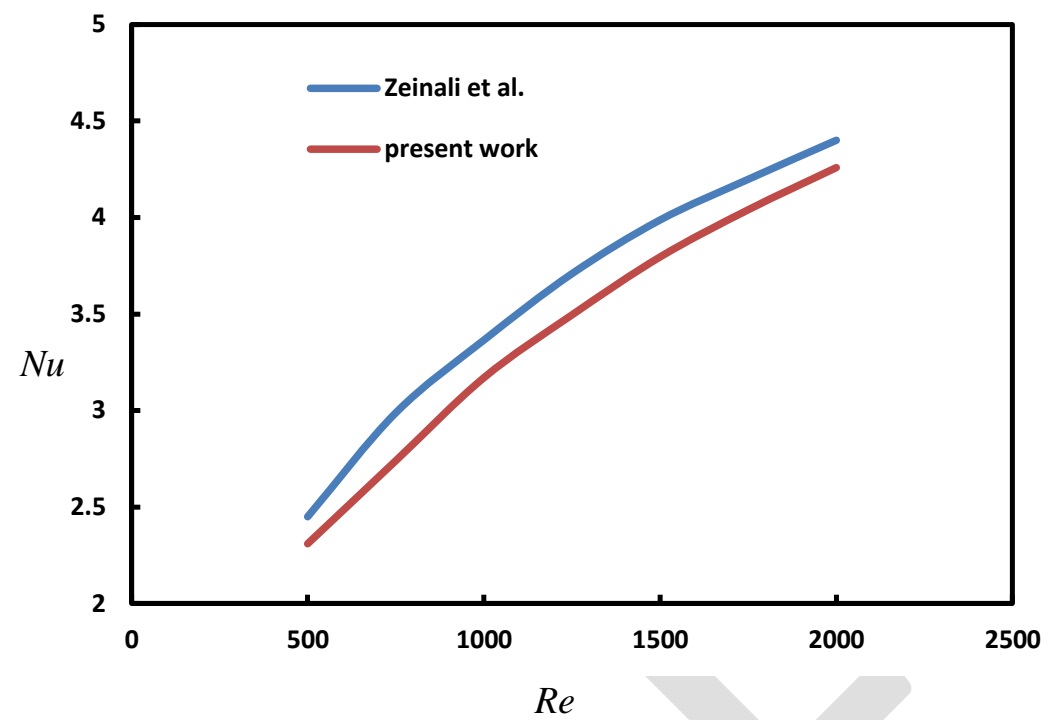

Fig.(4) Comparison between estimated results and results defined by model predictions of zeinali [13]

\section{VI.PROPERTIES OF NANOFLUID}

To calculate the flow field, the physical and thermal properties of nanofluids such as the density, specific heat, thermal conductivity and viscosity should be determined first based on the single phase model. All necessary properties of water and nanoparticles are listed in table(1).

-density $\rho_{n f}=(1-\phi) \rho_{f}+\phi \rho_{p}$

-heat capacity $(\rho C p)_{n f}=(1-\phi)(\rho C p)_{f}+\phi(\rho C p)_{p}$

-thermal conductivity $\frac{k_{n f}}{k_{f}}=\frac{k_{p}+2 k_{f}-2 \phi\left(k_{f}-k_{p}\right)}{k_{p}+2 k_{f}+\phi\left(k_{f}-k_{p}\right)}$

-viscosity $\mu_{n f}=\frac{\mu_{f}}{(1-\phi)^{2.5}}$

The volume fraction of the nanofluid can be formulate as:

$\phi=\frac{\text { volumeof particales }}{\text { volumeof nanofluid }}=\frac{m_{p} / \rho_{p}}{\left(m_{p} / \rho_{p}\right)+\left(m_{f} / \rho_{f}\right)}$

\begin{tabular}{|l|l|l|l|}
\hline Properties & water & $\mathrm{Al}_{2} \mathrm{O}_{3}$ & $\mathrm{CuO}$ \\
\hline Density $\left(\mathrm{Kg} / \mathrm{m}^{3}\right)$ & 998.2 & 3880 & 6500 \\
\hline Thermal Conductivity (W/m.k) & 0.597 & 36 & 400 \\
\hline Heat Capacity (J/Kg.k) & 4182 & 773 & 383 \\
\hline Viscosity () & $993 \mathrm{E}-6$ & & \\
\hline
\end{tabular}

Table (1). Thermal physical properties of water and nanofluid at $T=2980 \mathrm{~K}$ 


\section{International Journal of Innovative Research in Science, Engineering and Technology}

\section{(An ISO 3297: 2007 Certified Organization)}

\section{Vol. 3, Issue 8, August 2014}

Fig.(5) Variation of wall temperature distribution with time at $\mathrm{Q}=400 \mathrm{~W} / \mathrm{m}^{2}$ for different values and types of $(\phi)$
when $(\mathrm{A}) \mathrm{Re}=500$
B) $\mathrm{Re}=1000$
C) $\mathrm{Re}=1500$
D) $\mathrm{Re}=2000$
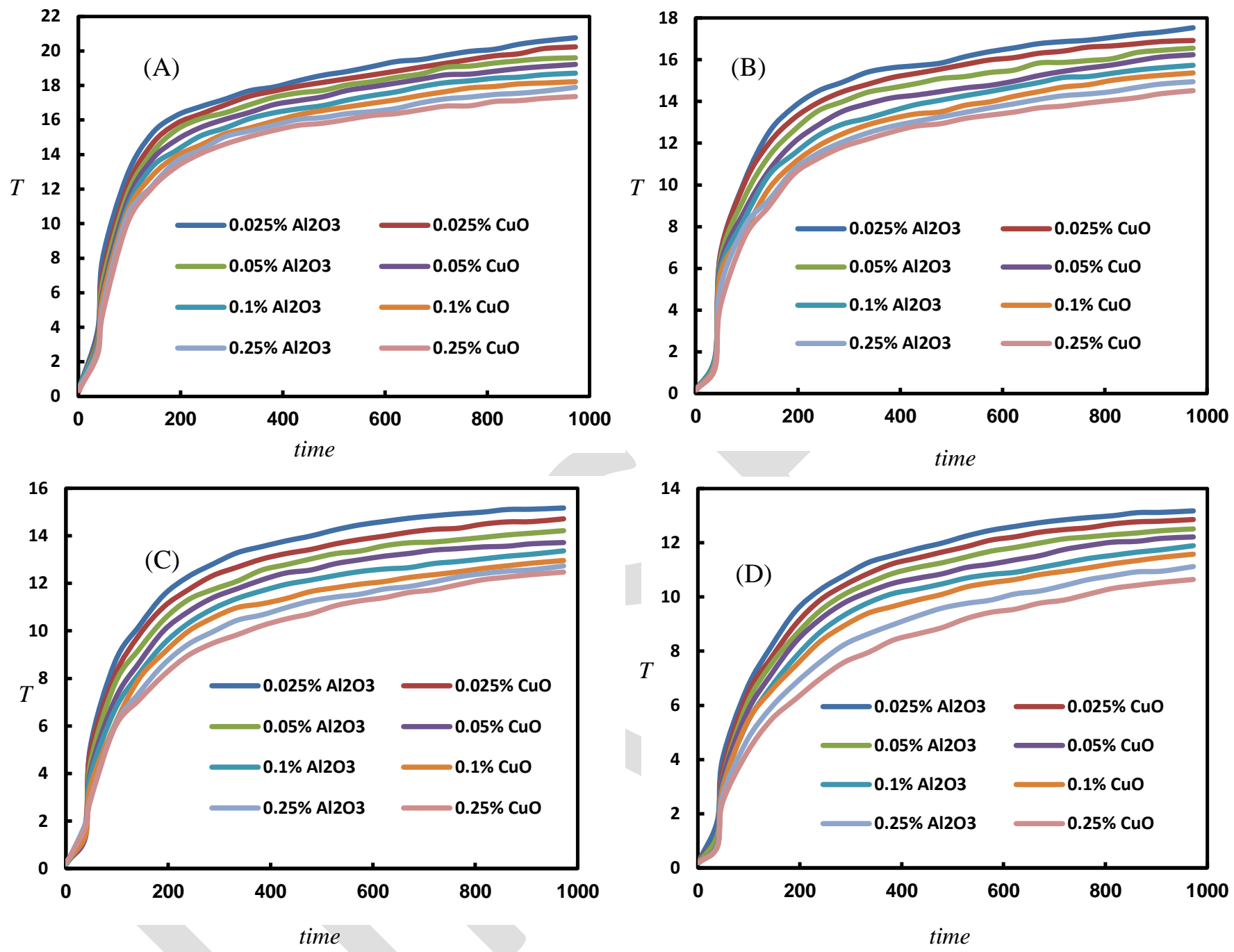

VII. RESULTS AND DISCUSSION

Heat transfer tests were performed on nanofluids at different volume fractions for both $\mathrm{Al} 2 \mathrm{O} 3$ and $\mathrm{CuO}(0.025 \%$, $0.05 \%, 0.1 \%$ and $0.25 \%$ and each experiment has been repeated two times at any rate. The temperatures are read directly along the axial direction of the duct and recorded momentarily with time. Figures (5 and 6) show the temperatures behavior with time for different values and types of $(\phi)$, Reynolds number, axial distance at time period. From figures (5 and 6 ) one can observe that the surface temperature increases rapidly at the beginning when the experiment is initiated. That is 


\section{International Journal of Innovative Research in Science, Engineering and Technology}

\section{(An ISO 3297: 2007 Certified Organization)}

\section{Vol. 3, Issue 8, August 2014}

Heat transfer tests were performed on nanofluids at different volume fractions for both $\mathrm{Al}_{2} \mathrm{O}_{3}$ and $\mathrm{CuO}(0.025 \%$, $0.05 \%, 0.1 \%$ and $0.25 \%$ and each experiment has been repeated two times at any rate. The temperatures are read directly along the axial direction of the duct and recorded momentarily with time. Figures (5 and 6) show the temperatures behavior with time for different values and types of $(\phi)$, Reynolds number, axial distance at time period. From figures (5 and 6) one can observe that the surface temperature increases rapidly at the beginning when the experiment is initiated. That is
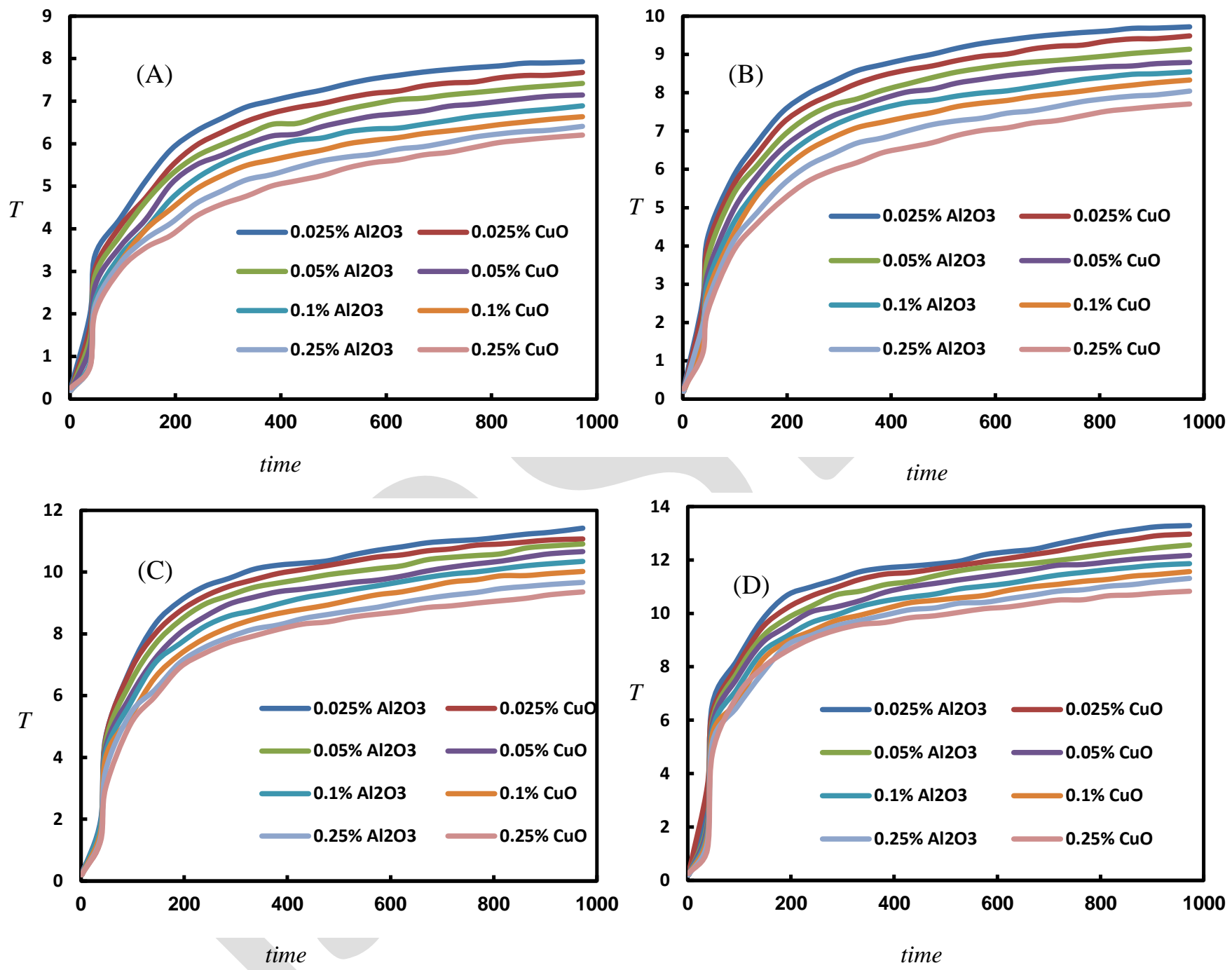

Fig.(6) Variation of wall temperature distribution with time at $Q=100 \mathrm{~W} / \mathrm{m}^{2}$ for different values and types of $(\phi)$ when $(\mathrm{A}) \mathrm{Re}=2000$
B) $\operatorname{Re}=1500$
C) $\operatorname{Re}=1000$
D) $\mathrm{Re}=500$ 


\section{(a) \\ IJIRSET \\ International Journal of Innovative Research in Science, Engineering and Technology}

ISSN: 2319-8753

\section{(An ISO 3297: 2007 Certified Organization)}

\section{Vol. 3, Issue 8, August 2014}

because of the high difference between initial wall temperature and that generated by applying heat flux and the direct contact between the heat source and the outer surface of the duct. The temperature profiles in figures (5) and (6) show gradual decreasing of temperatures distribution with time. Moreover, the temperatures distribution is disproportional to the value of $(\phi)$. This fact can be seen clearly with low Reynolds numbers due to low fluid velocity.
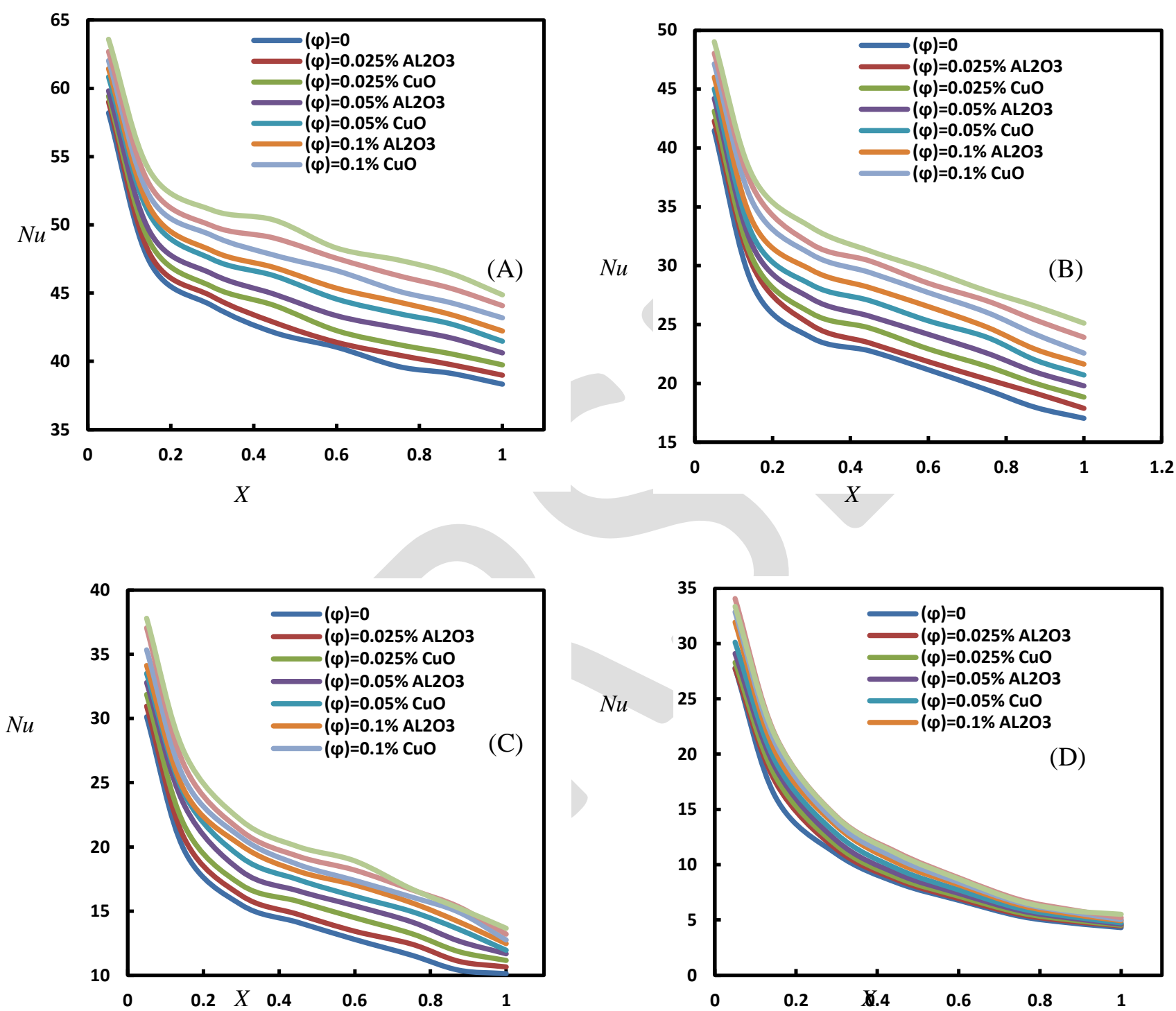

Fig.(7)Variation of Local $\mathrm{Nu}$ with tube length at $\mathrm{Re}=500$ and $\mathrm{Q}=100 \mathrm{~W} / \mathrm{m}^{2}$ for different values and types of
$(\phi)$ when $\mathrm{A}) \mathrm{t}^{*}=0.001$
B) $\mathrm{t}^{*}=0.01$
C) $\mathrm{t}^{*}=0.1$
D) $t^{*}=S S$

The considerable augmentation of heat reduction on walls can be explained due to continued impact and reflection of particles with the wall during motion. The particle itself conveys small amount of heat from the all and takes it back to the bulk. This semi-repeated process causes continued heat transfer from duct-wall to the fluid. It is worthy to mention that adding small amount of nanoparticles to the fluid would significantly increase the heat transfer in general. 


\section{(2) \\ IJIRSET \\ International Journal of Innovative Research in Science, Engineering and Technology}

ISSN: 2319-8753

\section{(An ISO 3297: 2007 Certified Organization)}

\section{Vol. 3, Issue 8, August 2014}

Moreover, the figures (5) and (6) provide a proof that increasing heat flux only with fixing the rest of the parameters causes increasing of $\left(T_{w}\right)$.

Figures (7) and (8) show the experimental results for the variation of local Nusselt number against the length of channel at constant Re. When the flow starts, the difference between the wall and nanofluid temperatures is maximum and hence, the $\mathrm{Nu}$ is maximum. Thereafter, the temperature differences becomes smaller continuously till the temperature difference comes to fixed value which represents the steady state condition. In general, for both nanofluids types $\mathrm{Nu}$ increases proportionally to the amount of loaded particles with comparison to base fluid. This fact is due to the following. Firstly, the nanofluid with suspended nanoparticles increases the thermal conductivity of the mixture.
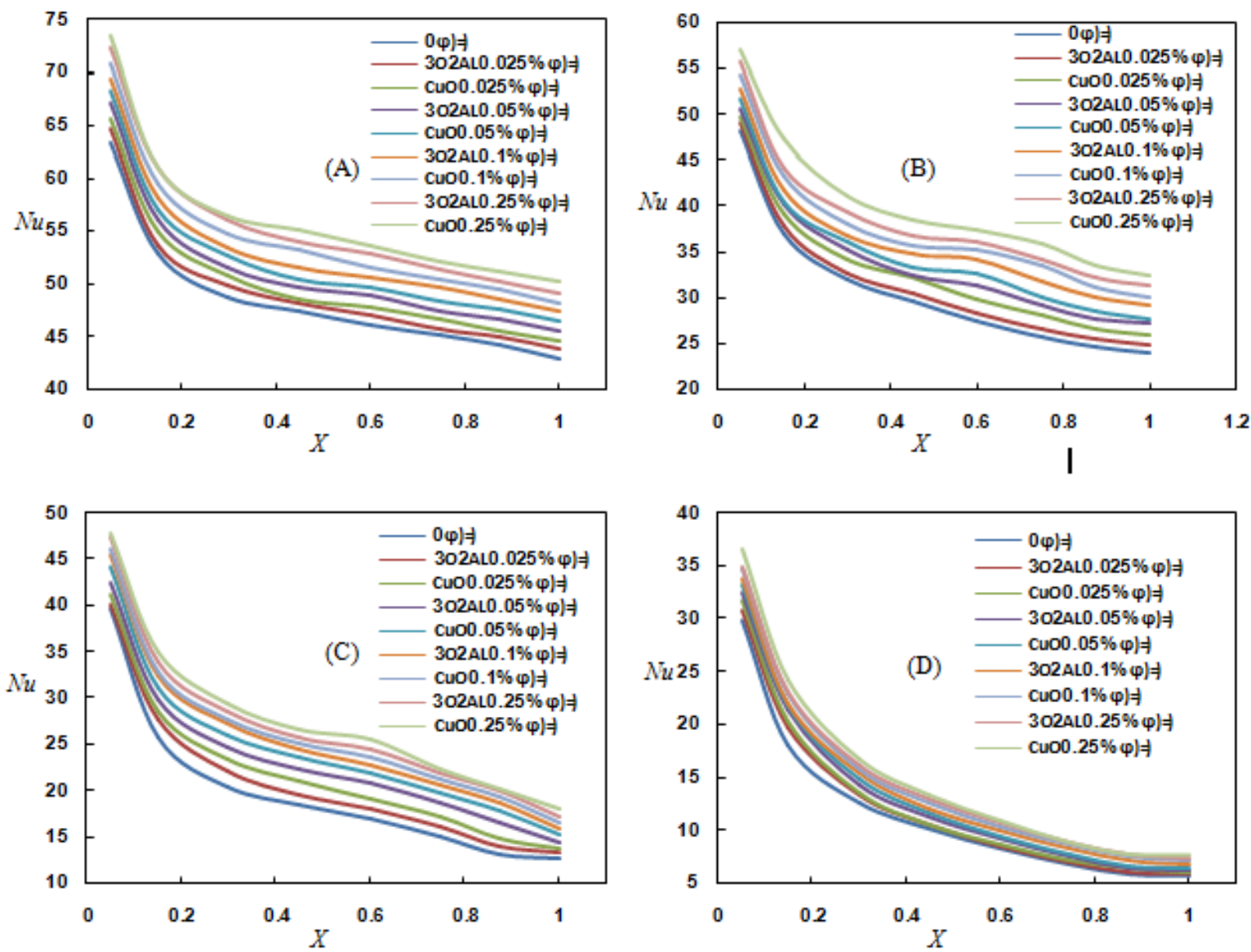

Fig.(8)Variation of Local Nu with tube length at $\mathrm{Re}=2000$ and $\mathrm{Q}=100 \mathrm{~W} / \mathrm{m}^{2}$ for different values and types of $(\phi)$ when
A)t* $=0.001$
B) $t^{*}=0.01$
C) $t^{*}=0.1$
D) $t^{*}=\mathrm{SS}$ 


\section{International Journal of Innovative Research in Science, Engineering and Technology}

(An ISO 3297: 2007 Certified Organization)

\section{Vol. 3, Issue 8, August 2014}

Fig.(9)Variation of $\left(T_{\text {out_ }} T_{\text {in }}\right)$ with $(\phi)$ at steady state condition for different values of Re when
A) $\mathrm{q}^{\prime \prime}=100 \mathrm{~W} / \mathrm{m}^{2}$
B) $\mathrm{q}^{\prime \prime}=200 \mathrm{~W} / \mathrm{m}^{2}$
C) $\mathrm{q}^{\prime \prime}=300 \mathrm{~W} / \mathrm{m}^{2}$
D) $\mathrm{q}^{\prime \prime}=400 \mathrm{~W} / \mathrm{m}^{2}$
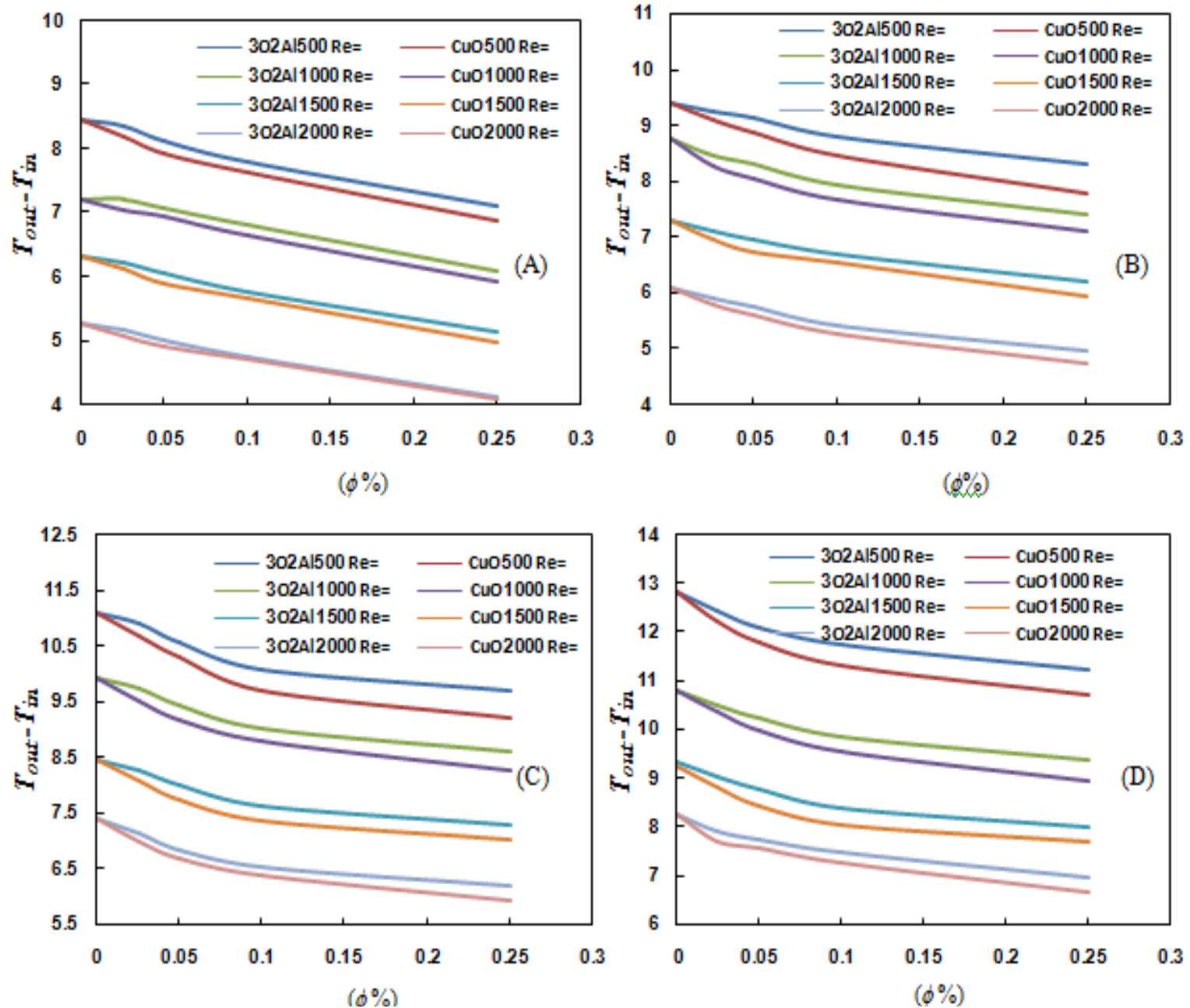

secondly, a large amount of energy exchanged process resulting from the chaotic movement of nanoparticles. The effect of increasing $(\phi)$ on the difference between outlet and inlet temperature $\left(\mathrm{T}_{\text {out }}-\mathrm{T}_{\text {in }}\right)$ for various heat flux and Reynolds number at steady state are presented in Figure (9).As shown in Fig. (9), the heat transfer difference appreciably decrease with augmentation of particle loading. Effects that explained by the fact that with the presence of such particles, the thermal properties of the resulting mixture become considerably more important. It can be evidently seen that the heat transformation of the nanofluid is higher than that of the base fluid (water) at a given heat flux. 


\section{International Journal of Innovative Research in Science, Engineering and Technology}

\section{(An ISO 3297: 2007 Certified Organization)}

\section{Vol. 3, Issue 8, August 2014}
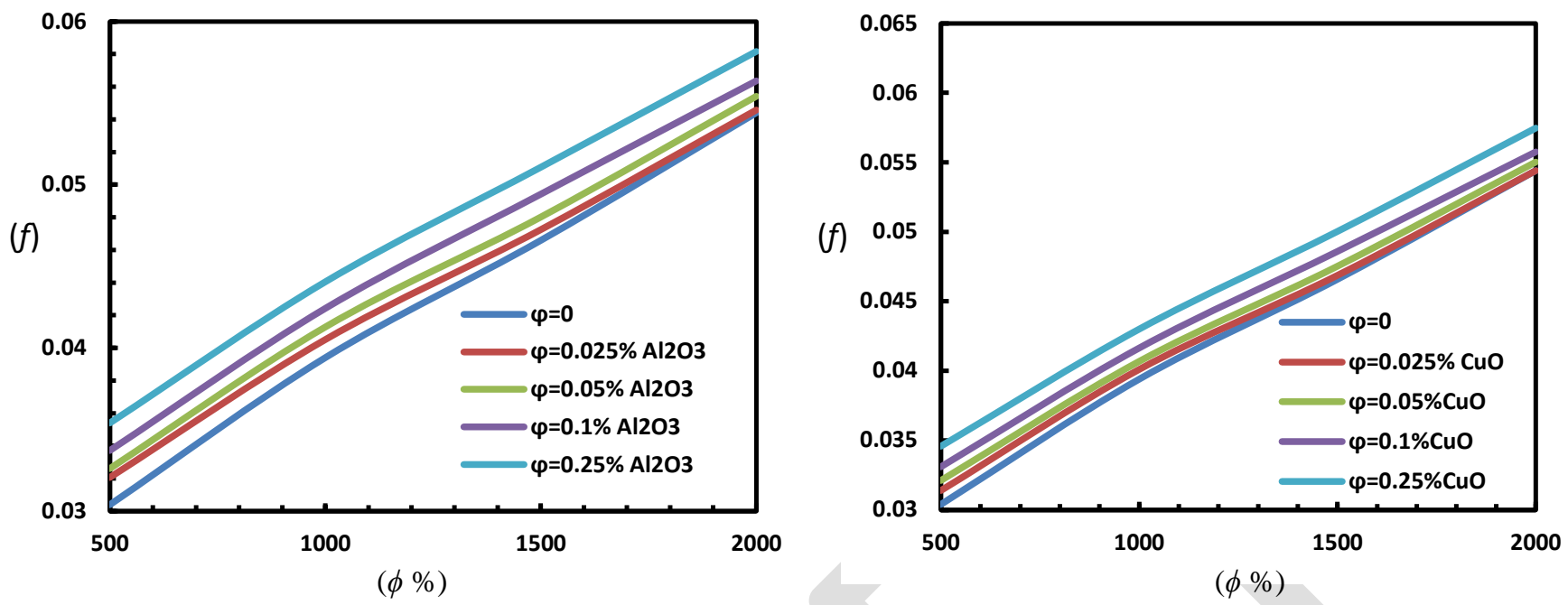

Fig.(10)Variation of friction factor with $\mathrm{Re}$ at $\mathrm{q}=100 \mathrm{~W} / \mathrm{m}^{2}$ for different values $(\phi)$ where $\quad \begin{array}{lll}\mathrm{A}) \mathrm{Al}_{2} \mathrm{O}_{3} & \mathrm{~B}) \mathrm{CuO}\end{array}$

The effect of the particles concentration on the friction factor is presented in Figure (10) for different $R e$. Usually, the friction factor is given as the ratio of the total pressure drop to the kinetic-energy losses. The friction factor $(f)$ increases slightly with the $(\phi)$ in addition to the increase in the flow rate and Reynolds number. At low flow rate, the friction factor related directly with pressure drop because the kinetic - energy losses are small. If the flow rate is high and particle loading is large, the kinetic - energy losses become significant, for that, the friction factor will be decreased. There are two main reasons lead to those results mentioned above, depending on fact that nanoparticles amount added is relatively small besides ultrafine of that particles sizes to behave as base fluid.

\section{CONCLUSIONS}

The model was carried out to simulate the transient forced convection flows of $\mathrm{CuO}-$ water and $\mathrm{AL}_{2} \mathrm{O}_{3}$-water nanofluid in a horizontal triangular duct for different Reynolds numbers and void fractions of nanoparticles. The results showed at a given Reynolds number, solid concentration has apositive effect on heat transfer enhancement. Also, there is an enhancement in heat transfer features where times for converting to steady state is lower than that of base fluid. In addition, the average Nusselt number is highly dependence on the void fraction. Comparison proofed that $\mathrm{CuO}$-water is better than $\mathrm{Al}_{2} \mathrm{O}_{3}$ in heat transformation process at the same conditions. It should be noticeable that additional works are need to be proficient in order to understand the major phenomena of the heat augmentation using the nanofluids at laminar flow regime.

\section{Nomenclature}

$C_{p} \quad$ Specific heat at constant pressure

$\mathrm{D}_{h} \quad$ Hydraulic diameter

$h \quad$ Heat transfer coefficient

$k \quad$ Thermal conductivity

L Duct length

$\mathrm{Nu} \quad$ Nusselt number

$\mathrm{p} \quad$ Pressure

q" Heat Flux $(\phi)$

$\mu$

$\rho$

Subscripts

bf

in

$w$

$P$

$n f$ solid volume fraction

dynamic viscosity

density

Bulk fluid

Inlet

Wall

particles

Nanofluid 
ISSN: 2319-8753

\section{International Journal of Innovative Research in Science, Engineering and Technology}

\section{(An ISO 3297: 2007 Certified Organization)}

\section{Vol. 3, Issue 8, August 2014}

$\begin{array}{lc}\text { Re } & \text { Reynolds number } \\ \mathrm{T} & \text { Temperature } \\ t & \text { Time } \\ \text { Greek } & \text { symbols } \\ \alpha & \text { thermal diffusivity }\end{array}$

\author{
$x$ \\ $o$ \\ Local position
Outlet
}

\section{REFRENCES}

[1] Li, Q., and Xuan, Y. "Heat transfer enhancement of nanofluids”, International Journal of Heat and Fluid Flow, Vol.21, pp.58-64, 2000.

[2] Kang, H.U., Kim, S.H., and Oh, J.M., "Estimation of thermal conductivity of nanofluid using experimental effective particle volume", Experimental Heat Transfer Vol.9, pp.181-191, 2006

[3] Trisakasri, V., and Wongwises, S., "Critical review of heat transfer characteristic of nanofluids", Renewable and sustainable energy reviews, Vol.11, pp.512-523, 2007.

[4] Daungthongsuk, W., and Wongwises, S., "A critical review of convective heat transfer of nanofluids", Renewable and sustainable energy reviews, Vol.11, pp.797-817, 2007.

[5] Jung, J.Y., Oh, H.S., and Kwak, H.Y., "Forced convective heat transfer of nanofluids in microchannels," International Journal of Heat and Mass Transfer, Vol.52, pp.466-472, 2009.

[6] Li, Q., and Xuan, Y., "Convective heat transfer and flow characteristic of Cu-Water nanofluid”, Science in China, Series E, Vol.45, pp.408-416, 2004.

[7] Xuan, Y., and Li, Q., "Investigation on convective heat transfer and flow features of nanofluids", ASME Journal of Heat Transfer, Vol.125, pp.151-155, 2003.

[8] Yang, Y., Zhang, Z.G., Grulke, E.A., Anderson, W.B., and Wu, G. "Heat transfer properties of nanoparticle in fluid dispersions in laminar flow", International Journal of Heat and Mass Transfer Vol.48, pp.1107-1116, 2005.

[9] ZeinaliHeris, S., Etemad, SGh., Nasr Esfahany, M. "Experimental investigation of oxide nanofluid laminar flow convective heat transfer in circular tube", International Communication in Heat and Mass Transfer, Vol.33, pp. 529-533, 2006.

[10] ZeinaliHeris, S., Nasr Esfahany, M., Etemad, SGh., "Experimental investigation of convective heat transfer of $\mathrm{Al}_{2} \mathrm{O}_{3} / \mathrm{Water}$ nanofluid in circular tube", International Journal of Heat and Fluid Flow, Vol.28, pp.203-210, 2007

[11] Nassan, T.H., Zeinali Heris, S., and Noie, S.H., "A comparison of experimental heat transfer characteristics for $\mathrm{Al}_{2} \mathrm{O}_{3} /$ water and $\mathrm{CuO}_{\text {water }}$ nanofluids in square cross-section duct", International Communications in Heat and Mass Transfer Vol.37, pp.924-928, 2010.

[12] Yimin Xuana, and Wilfried Roetzel, "Conceptions for heat transfer correlation of nanofluids", International Journal of Heat and Mass Transfer, Vol.43, pp.3701-3707, 2000.

[13] Saeed Zeinali Heris, Seyyed Hossein Noie, Elham Talaii, and Javad Sargolzaei, "Numerical investigation of $\mathrm{Al}_{2} \mathrm{O}_{3} / \mathrm{water}$ nanofluid laminar convective heat transfer through triangular ducts", Nanoscale Research Letters,Vol.6, pp.179-188, 2011.

[14] ] Akbari, M., Galanis N., and Behzadmehr, A., "Comparative analysis of single and two-phase models for CFD studies of nanofluid heat transfer”, International Journal of Thermal Sciences, Vol.50, pp.1343-1354, 2011. 